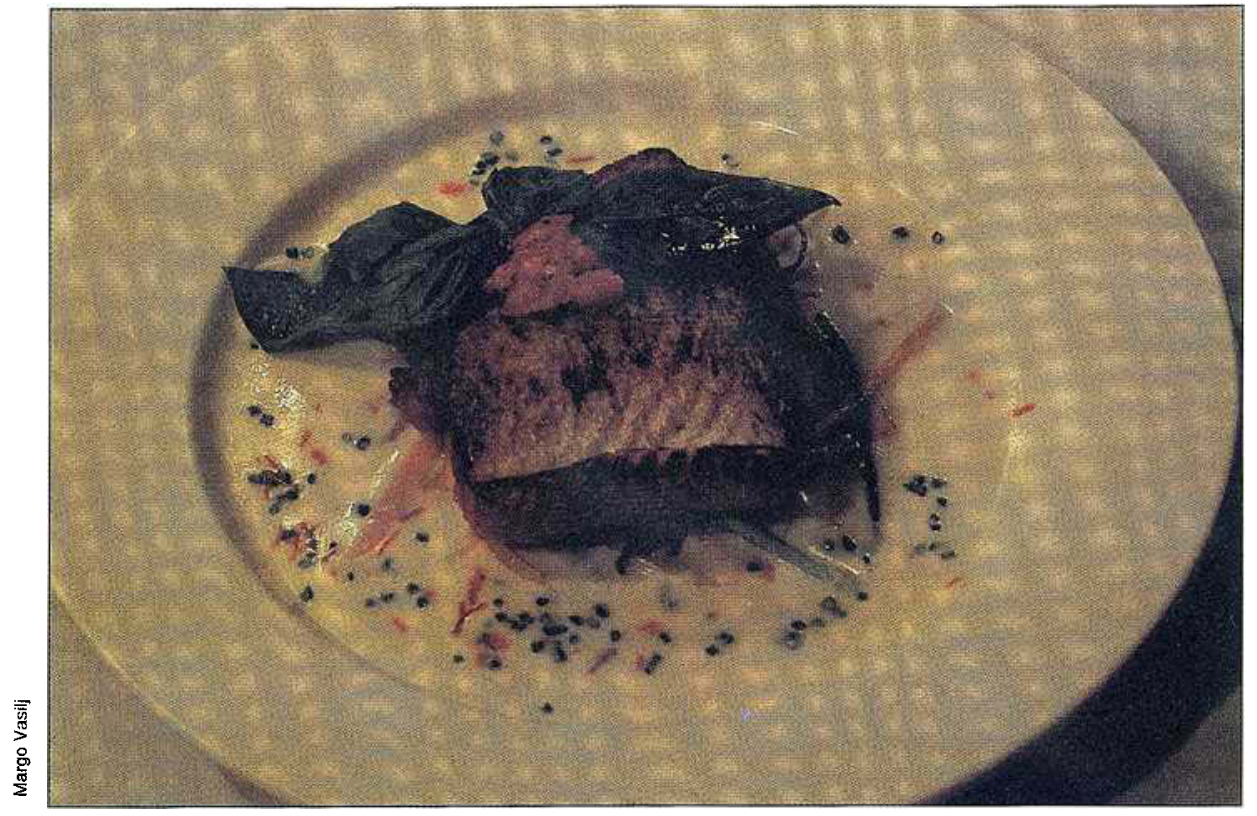

Southern California restaurants are increasing their use of fresh culinary herbs. Opportunities exist for well-placed growers to take advantage of the restauranteurs' desire to deal directly with farmers.

\title{
Culinary herb use in southern California restaurants
}

\section{Stephen H. Brown}

Fresh culinary herbs have become an important part of southern California'scuisine. Restauranteurs are interested in enhancing the flavor of foods without increasing the foods' caloric, sugar, salt, and cholesterol contents. Local restaurants have led the way in developing and popularizing the use of fresh herbs. This shift to natural flavor enhancers is in keeping with today's lifestyle of healthier, lighter meals.

Recognizing restauranteurs' special link with trends in food consumption, we conducted this survey to (1) provide farmers with information useful for marketing fresh herbs in the southern California area, (2) assist Farm Advisors and Extension Specialists in making recommendations on herb marketing, and (3) inform the restaurant industry about the extent to which fresh herbs are used in top southern California restaurants.

\section{Sampling methods}

For this survey, we selected 500 of southern Californias' "outstanding" restaurants as listed in a 1989 publication of top restaurants in the Los Angeles area. Restaurants were located as far south as San Diego, as far east as Palm Springs, and as far north as Santa Barbara. In the summer of 1989 , we mailed a questionnaire to the chef or manager of each surveyed restaurant, asking that it be returned within two weeks. Out of a mailing of 500,87 surveys were returned and analyzed.

Of the returns, $75 \%$ were from restaurants inLos Angeles County, $9 \%$ each from Orange and San Diego counties, and 6\% from Santa
Barbara County. Respondents could identify their restaurants as either American, Asian, Californian, Continental/International, French, or Mediterranean.

\section{Changes in fresh herb use}

Mostchefs and restaurant managers (29.8\%) said they learn of new fresh herbs through food and restaurant magazines (fig. 1). Communication among chefs and contact with farmers ranked second $(17.9 \%)$ and third (16.4\%), respectively, as avenues to new culinary herb use. Purveyors ranked fourth $(14.9 \%)$ as a source for information on new herbs for the restaurant industry. Since purveyors play theleading rolein supplying

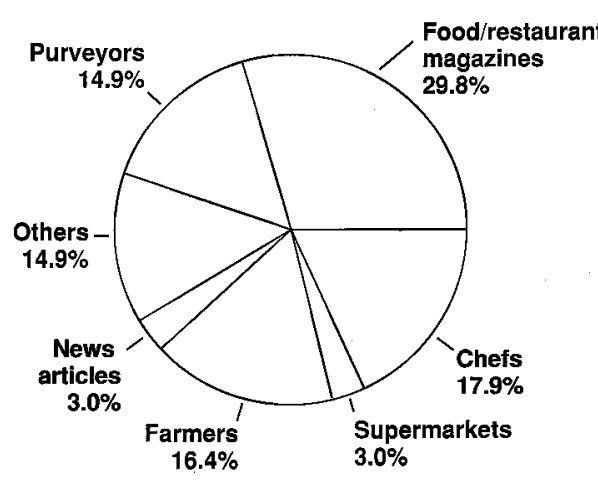

Fig. 1. Where the chefs of surveyed southern California restaurants learn of the use of different culinary herbs. fresh herbs to top California restaurants, they may be able to stimulate the usage of particular herbs through a better collective use of the media or increased appeals to restauranteurs.

Other avenues for the introduction of fresh herbs include the popular press $(3.0 \%)$, and supermarkets (3.0\%). Respondents also listed garden magazines, food shows, and television.

\section{Reason for usage}

The vast majority of respondents (96.5\%) use fresh herbs in food preparation or presentation. When asked to selectall applicable reasons from a list, an overwhelming majority of respondents $(93.9 \%)$ indicated they use fresh herbs for the added flavor. Many also use herbs for the aroma (74.1\%), and almost as many $(68.3 \%$ ) use fresh herbs for garnishing. A minority (27.1\%) use herbs for customer education, and fewer still (20.7\%) use culinary herbs for health benefit.

\section{Sources of fresh herbs}

Many of the responding restaurants (45.8\%) receive the bulk of their fresh herbs from local purveyors (fig. 2). Wholesale markets supply $26.4 \%$ of the restaurants with most of their fresh herbs, and farmers deliver most the fresh herbs to a fifth of the restaurants. A few restaurants $(5.6 \%)$ grow most of their fresh herbs themselves; and only $1.4 \%$ of respondents purchase most of their fresh herbs from local supermarkets.

When asked from which source they would prefer to obtain most of their fresh 
herbs, most restaurants chose decisively in favor of the farmer (42.9\%), while $26.0 \%$ prefer to continue to work through a purveyor. This is in direct contrast to the current market situation, where restaurant purveyors dominate the distribution of fresh herbs. Marketing opportunities therefore appear to exist for local farmers willing to supply fresh herbs directly to restaurants.

A minority of restaurants (15.6\%) would like to attempt to grow most of their fresh herbs. Another $13.0 \%$ prefer to continue purchasing from the downtown produce market, and $1.3 \%$ would continue using supermarkets as a major source.

Growing conditions are considered by some respondents to be important in selecting fresh herbs. For aroma and flavor, $56.2 \%$ prefer field grown herbs, $3.8 \%$ prefer hothouse (greenhouse) grown herbs, and $40.0 \%$ see no difference. Respondents split about evenly on organically grown herbs: $44.4 \%$ prefer organically grown herbs, but $45.7 \%$ see no difference between organic and non-organic production.

\section{Most commonly used herbs}

The number-one fresh herb, selected most often as one of the three most commonly used herbs, is sweet basil, as indicated by $79.0 \%$ of respondents over all restaurant types. Thyme and cilantroare tied for second, with $32.1 \%$ each. Table 1 ranks the herbs most commonly used by surveyed southern California restaurants.

Basil is also the most commonly used herb for each restaurant type. Itranks among the top three herbs for $93.3 \%$ of California-

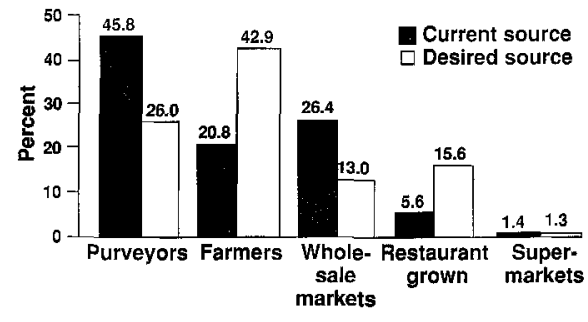

Fig. 2. Southern California restauranteurs' current and desired sources for purchase of culinary herbs.

style restaurants, $92.3 \%$ of Mediterranean restaurants, $80.0 \%$ of Asian restaurants, $84.2 \%$ of French restaurants, and $70.0 \%$ of both American and Continental/International restaurants (table 2 ).

The second most popularly used herb varied with type of restaurant. Mint was tied with basil for first place in Asian restaurants $(80 \%)$ and placed second $(50.0 \%)$ in American-style restaurants. Rosemary placed second in Mediterranean restaurants (76.9\%). Other second-place finishers included cilantro $(60.0 \%$ of Continental/International restaurants) and thyme (53.3\% ofCalifornianstyle restaurants and $50.0 \%$ of Americanstyle restaurants, where it is tied with the use of mint).

\section{Amount used}

Results of the survey indicate that $39 \%$ of restauranteurs increased their use of fresh herbs over the preceding year. Sixty-one percent of chefs and restaurant managers indicated that fresh herb consumption had remained the same when compared to the previous year. No onereported a decrease in

TABLE 1. Percentage of respondents listing each herb as among the three most commonly used

\begin{tabular}{llc}
\hline \hline Common name & Botanical name & Percentage \\
\hline Basil & Ocimum basilicum & 79.0 \\
Thyme & Thymus vulgaris & 32.1 \\
Cilantro (Coriander) & Coriandrum ambrosioides & 32.1 \\
Rosemary & Rosmarinus officinalis & 23.5 \\
Parsley & Petroselinum crispum & 22.2 \\
Mint & Mentha spp. & 21.0 \\
Tarragon & Artemisis dracunculus & 21.0 \\
Dill & Anethum graveolens & 14.8 \\
Oregano & Origanum spp. & 13.6 \\
Chives & Allium schoenoprasum & 8.6 \\
Sage & Salvia officinalis & 8.6 \\
Chervil & Anthriscus cerefollum & 4.9 \\
Lemongrass & Cymbopogon citratus & 1.2 \\
Epazote & Chenopodium ambrosioides & 1.2 \\
Sorrell & Rumex spp. & 1.2 \\
Watercress & Nasturtium officinale & 1.2 \\
\hline
\end{tabular}

TABLE 2. The three mostuused herbs, according to restaurant type Cuisine

\begin{tabular}{|c|c|c|c|c|c|c|}
\hline Herb & American & Asian & California & $\begin{array}{l}\text { Continental/ } \\
\text { international }\end{array}$ & French & $\begin{array}{c}\text { Mediter- } \\
\text { ranean }\end{array}$ \\
\hline Basil & 1 & 1 & 1 & 1 & 1 & 1 \\
\hline Thyme & 2 & 3 & 2 & - & 2 & - \\
\hline Cilantro & 3 & - & 3 & 2 & - & - \\
\hline Rosemary & - & - & - & - & - & 2 \\
\hline Parsley & - & - & - & - & - & 3 \\
\hline Mint & 2 & 1 & - & - & - & - \\
\hline Tarragon & 二 & 3 & - & 3 & - & - \\
\hline Chives & - & - & - & - & 3 & - \\
\hline Sage & - & - & - & - & - & 3 \\
\hline Lemongrass & - & 2 & - & - & - & 3 \\
\hline
\end{tabular}

fresh herb use. The median restaurant consumption of fresh herbs is 10 pounds a week. Restauranteursspend moreto purchase fresh herbs in winter than in summer, and purchase slightly smaller amounts in winter. For all restaurants, the median weekly expenditure was $\$ 80.00$ in summer and $\$ 87.00$ in winter.

Asian restaurants' median weekly purchase $(3.8 \mathrm{lb}$. and $\$ 37.50 /$ week, both summer and winter) is less than for all other restaurant types. Mediterranean restaurants' expenditure on fresh herbs exceeds that of all other restaurant types $(\$ 200.00 /$ week, summer and winter). Mediterranean restaurants purchase a median quantity of $11 \mathrm{lb} /$ week year-round.

French restaurants' median expenditure on fresh herbs was $\$ 100.00 /$ week in the summer and $\$ 105.00 /$ week in the winter. Annual median use was estimated at $9.0 \mathrm{lb} /$ week. American-style restaurants' median winter expenditures on fresh herbs $(\$ 87.50)$ falls below summer expenditures $(\$ 100.00)$. Continental/International and Californiastyle restaurantsalso reported a dip in winter expenditures. The shortage of fresh herbs in the winter resulting from unfavorable growing conditions is the probable cause of reduced expenditures for these restaurants.

Farmers growing herbs for the restaurant trade may be interested to know that Asian restaurants appear to require fewervarieties (five herbs) and fewer pounds ( $3.81 \mathrm{lb} /$ week) than other restaurant types. A grower's average weekly income for sales to an Asian restaurant may not exceed $\$ 37.50$. This may result partly from the extensive use of dried herbs and spices in many Asian dishes. French restaurants use the greatest variety of herbs (13 herbs), followed by Californiastyle restaurants (11 herbs). Results of the survey indicate that as many as ten varieties of herbs are commonly used in Mediterranean and American-style cuisines.

When growing herbs for a particular type of restaurant, a grower should consider the many herb varieties used by the restaurants as well as the restaurants' average weekly expenditures for these herbs. When asked if they would be willing to spend more for fresh herbs, $56.4 \%$ of respondents said they would, provided that quality, quantity, and varietal selections improved.

Finally, the vast majority $(90.4 \%)$ of responding chefs and restaurant managers believed that herb usage would continue to grow. A minority (8.4\%) thought herb usage had leveled off, and fewerstill (1.2\%) thought it was a passing fad.

\section{Limitations on use}

Most respondents $(64.8 \%)$ indicated that there are no significant limitations on their use of fresh herbs. Those who indicated that there are limitations on their use of fresh herbs were asked to rank the limiting factors from 1 to 10 , using a list of 10 suggested 
limitations. High cost was cited most often $(63.6 \%)$. Short storage life ranked second $(50.0 \%)$. Poor quality was considered to be a limiting factor by $36.4 \%$ of respondents.

The unavailability of some herbs was ranked by $31.8 \%$ of respondents as limiting their use of fresh herbs. Chervil was listed by $5.9 \%$ of all respondents as the least available herb. Basil, epazote and lavender all tied for second place as the herbs that restauranteurs have the most trouble finding. Other herbs that were difficult to find included opal basil, mint sorrell, tarragon, and thyme. Lavender, one of the hardest-to-find herbs, was not listed among the 16 herbs most commonly used by southern California's restauranteurs.

The hardest herbs to find are not necessarily the ones most sought by restauranteurs. Chervil, used by $4.9 \%$ of respondents (table 1), was reported hard-toobtain by $5.9 \%$ of respondents. This might indicate that all or part of the $4.9 \%$ still had trouble locating sufficient quantities of chervil, or that an additional $5.9 \%$ of respondents would use chervil if it were available to them. In either case, the percentage of chefs using chervil would probably not exceed $10.0 \%$.

\section{Conclusions}

Southern California's top restaurants routinely incorporate fresh herbs into their menus, and fresh herb usage will probably continue to grow. Restauranteurs would like to get fresh herbs directly from local growers. These results should encourage farmers wanting to make direct sales to local restaurants.

No one is working in an organized way to keep restauranteurs informed on the usage and availability of new and established varieties of fresh herbs. An organized marketing effort by growers and purveyors might help increase the quantity of fresh herbsused by restaurants, and subsequently by consumers.

High cost was the factor most often cited as limiting the increased sales of herbs. However, most restauranteurs indicated their willingness to pay more for fresh herbs, provided there was a corresponding improvement in quality, quantity, and varietal selection.

Whilemostsurveyed restaurants use basil extensively, growers should tailor their varietal production to suit specific cuisines or chefs. Agrower may profitmore, for instance, by selling directly to Mediterranean restaurants, and may berequested togrow a greater variety of fresh herbs by French restaurants.

Stephen H. Brown is Cooperative Extension Farm Advisor, Los Angeles County. Thanks to Carol Adams, Statistician, at UC Riverside. Partial funding for this survey was provided by the California Restaurant Association, Los Angeles.

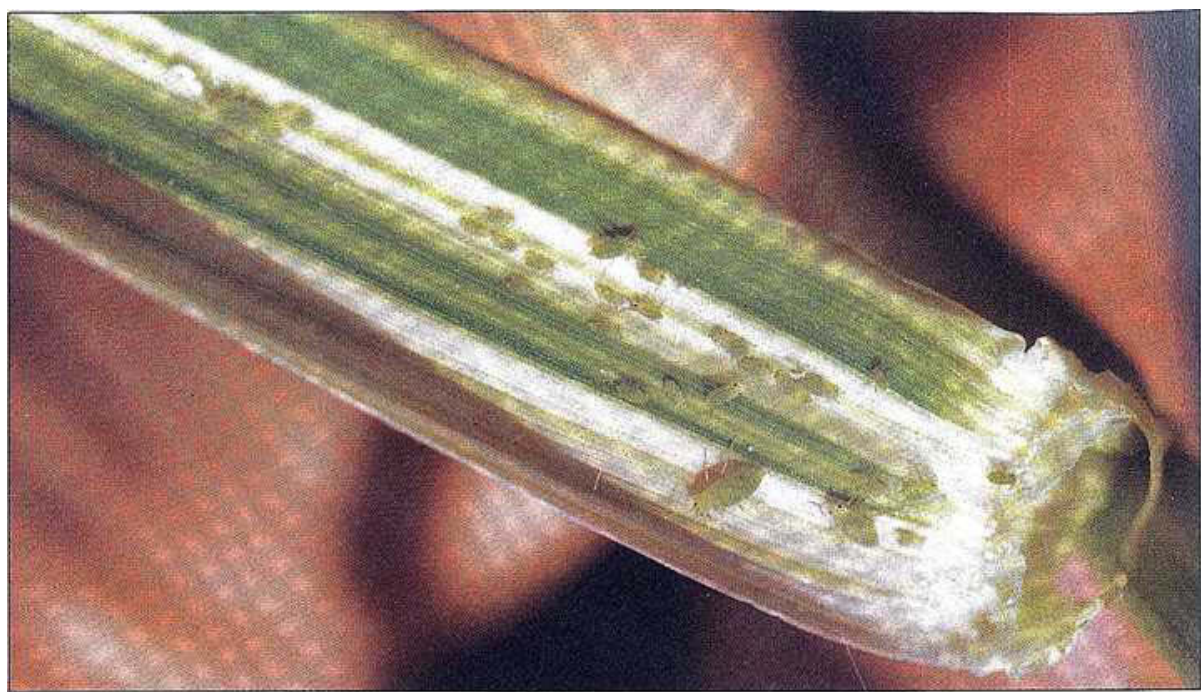

\section{Controlling Russian wheat aphid in California}

\author{
Vernon M. Stern $\square \quad$ Steve B. Orloff
}

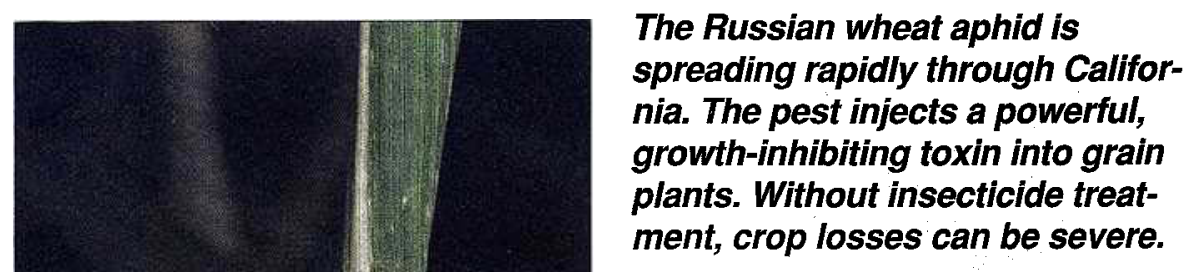

The Russian wheat aphid (RWA), Diuraphis noxia (Mordvilko), was first discovered in the United States near Lubbock, Texas, in 1986. It has now spread to all states from Texas to North Dakota and westward to the Pacific Ocean. It can also be found in central and western Canada. RWA was found in 1988 in Imperial County, California, and has now spread to most grain production areas of the state. No important biological control agents are currently being used to suppress RWA.

Russian wheat aphid is a serious pest of wheat, barley, triticale, and rye. Mostreports from the Midwest and from our own field trials indicate that oats is a poor host for RWA. Several species of native and introduced grasses (Bermuda grass, ripgut brome, rescue grass, and foxtail barley) will support RWA populations. Besides cultivated cereal grains, several species of range grasses may be attacked.

Small grains constitute a substantial 瞦 acreage in California. In 1989, wheat and 추 barley totaled 1.5 million acres with a value of $\$ 255$ million. Oats and barley grown for hay constitute additional acreage and dollar value. Economic losses attributable to RWA can be categorized as reduced yields, loss of kernel weight and quality, livestock grazing 